Adebayo A Adewole. Haematological and biochemical effects of etonogestrel subdermal implant (Implanon) in Ilorin Nigeria. International Journal of Health Science, Qassim University. 2016 Oct; 10(4): 499-506.
9. Perez, M. J., Squires, K. J., Parks, L., \& Peipert, J. F. Perceived weight gain among adolescents using contraception. Journal of Pediatric and Adolescent Gynecology. 2015 Apr 28(2), e70.

\title{
ĐĂC ĐIỂM HÌNH ẢNH VÀ GIÁ TRI CỦA CộNG HƯởNG TỪ TRONG CHẨN ĐOÁN UNG THƯ ĐƯỜNG MÂTT RỐN GAN
}

\section{TÓM TẮT}

Mục tiêu: Mô tả đặc điểm hình ảnh cộng hưởng từ của ung thư đường mật rốn gan, giá trị của cộng hưởng từ trong chẩn đoán xác định và chẩn đoán giai đoạn bệnh. Đối tượng nghiên cứu: Mô tả tiến cứu gồm 35 bênh nhân với chẩn đoán lâm sàng ung thư đường mật rốn gan và được chụp cộng hưởng từ tại bênh viên Hữu Nghi Viêt Đức tứ tháng 7 năm 2019 đến tháng 7 năm 2021. Kết quả: Kích thước trung bình của thể khối và thể phát triển trong lòng đường mật $3,86 \pm 1,77 \mathrm{~cm}$; với thể thâm nhiễm, độ dày thành đường mât trung bình $6,53 \pm 4,04 \mathrm{~mm}$, chiểu dài đoan dày là $25,47 \pm 6,87 \mathrm{~mm}$. Trên chuỗi xung $\mathrm{T} 1 \mathrm{~W}$, phẩn lớn u giảm hoăcc đồng tín hiệu $(93,8 \%)$, tín hiệu trên chuối xung T2W thay đổi. 96,8\% trường hợp u hạn chế khuếch tán trên DWI. CHT có đô̂ nhạy $100 \%$, độ đặc hiệu 25\%, giá trị dự báo dương tính 91,2\%, giá trị dự báo âm tính 100\%, độ chính xác $91,4 \%$ trong chẩn đoán ung thư đường mât rốn gan. $\mathrm{CHT}$ chẩn đoán đúng giai đoạn 83,9\% trường hợp. Kết luân: Ung thư đường mâtt rốn gan thường giảm hoặc đổng tín hiệu trên chuỗi xung T1W, tín hiệu thay đổi trên chuỗi xung T2W, hạn chế khuếch tán trên DWI. Cộng hưởng từ là phương pháp rất có giá trị trong chẩn đoán và đánh giá giai đoan của ung thư đường mât rốn gan.

Tư khóa: ung thư đường mật rốn gan, cộng hưởng từ, chẩn đoán giai đoạn.

\section{SUMMARY}

\section{IMAGING CHARACTERISTICS AND VALUES OF MAGNETIC REASONANCE IMAGING IN THE DIAGNOSIS OF HILAR CHOLANGIOCARCINOMA}

Objectives: Describing imaging characteristics, assessing values of MRI in the diagnosis and staging of hilar cholangiocarcinoma. Patients and methods: 35 patients suspected of hilar cholangiocarcinoma who had undergone MRI in Viet Duc Hopital were selected to be in a descriptive study from July 2019 to July 2021. Results: Average size of mass-forming and

\footnotetext{
${ }^{1}$ Bệnh viện Hữu nghi Việt Đức

${ }^{2}$ Trường đại họ Y Hà nọi

Chịu trách nhiệm chính: Lê Thanh Dũng

Email: drdung74@gmail.com

Ngày nhân bài: 25.6.2021

Ngày phản biên khoa họ: 20.8.2021

Ngày duyệt bài: 27.8.2021
}

\section{Lê Thanh Dũng1, Nguyễn Thanh Vân Anh²}

intraductal growing type was $3,86 \pm 1,77 \mathrm{~cm}$. With periductal infiltrating type, average wall thickness was $6,53 \pm 4,04 \mathrm{~mm}$; average segment involvement was $25,47 \pm 6,87 \mathrm{~mm}$. On T1W imaging, majority of tumors were hypointense or isointense $(93,8 \%)$, the signal intensity was variable on T2W imaging. $96,8 \%$ tumors showed restricted diffusion. MRI had sensitivity $100 \%$, specificity $25 \%$, positive predicted value $91,2 \%$, negative predicted value $100 \%$, accuracy $91,4 \%$ in the diagnosis of hilar cholangiocarcinoma. Accuracy for ductal extent for MRI was 83,9\%. Conclusion: Hilar cholangiocarcinoma is typically hypointense or isointense on T1W, restricted diffusion on DWI, the signal intensity is variable on T2W. MRI is a valuable method in diagnosis and staging hilar cholangiocarcinoma.

Key words; hilar cholangiocarcinoma, magnetic reasonance imaging, diagonis.

\section{I. ĐăT VẤN ĐỀ}

Ung thư đường mật (UTĐM) rốn gan hay u Klatskin, lân đâu tiên được mô tả năm 1965 [1] là bệnh lý ác tính xuất phát từ biểu mô của đường mật từ chỗ ống gan phải và trái hợp lại thành ống gan chung đến chỗ ống túi mật đổ vào ống gan chung. Đây là vị trí hay gặp nhất trong ung thư đường mật, đứng thứ 2 sau ung thư gan nguyên phát, tiên lượng xấu.

Nhóm nghiên cứu ung thư gan Nhật Bản phân loại UTĐM làm 3 thể: thể khối, thể thâm nhiễm quanh đường mật và thể phát triển trong đường mật [2]. Siêu âm và chụp cắt lớp vi tính được sử dụng phổ biến nhưng khó đánh giá được toàn bộ hệ thống đường mật. Hiện tại, cộng hưởng từ (CHT) được đánh giá là phương pháp chẩn đoán hình ảnh tối ưu cho các bệnh lý gan mật tụy nói chung cũng như ở bệnh nhân ung thư đường mật nói riêng. Sự kết hợp các chuỗi xung $\mathrm{CHT}$ quy ước (conventional MRI) và CHT mật tụy (MRCP) cho phép khảo sát toàn bộ cây đường mật, ống tụy, nhu mô gan, đánh giá mức độ lan rộng của u, mức độ xâm lấn mạch máu, di căn hạch, di căn gan và di căn các cơ quan lân cận trên bệnh nhân ung thư đường mật [3]. Tại Việt Nam đã có đề tài nghiên cứu về giá trị CHT trong chẩn đoán UTĐM rốn gan tuy 
nhiên thực hiện trên máy có cường độ từ trường thấp 0.3 Tesla. Vì vậy, nhân 35 trường hợp UTĐM rốn gan được chụp CHT tại bệnh viện Hữu nghị Việt Đức, chúng tôi tiến hành nghiên cứu: " Đặc điểm hình ảnh và giá trị của cộng hưởng từ trong chẩn đoán ung thư đường mật rốn gan".

\section{II. ĐỐI TƯỢNG VÀ PHƯƠNG PHÁP NGHIÊN CỨU}

2.1 Đối tượng nghiên cứu: 35 bệnh nhân với chẩn đoán lâm sàng UTĐM rốn gan được chụp CHT tại bệnh viện Hữu nghị Việt Đức trong thời gian từ tháng 7/2019 đến tháng 7/2021.

2.2 Tiêu chuẩn lựa chọn: Các bệnh nhân có triệu chứng lâm sàng, xét nghiệm nghi ngờ UTĐM rốn gan đến khám tại Bệnh viện Hữu nghị Việt Đức; được chụp CHT ở máy có cường độ từ trường 1.5Tesla, sau đó sinh thiết hoặc phẫu thuật (có kết quả giải phẫu bệnh) là UTĐĐ rốn gan, đồng ý tham gia nghiên cứu, có hồ sơ lưu trữ đầy đủ.

2.3 Tiêu chuẩn loại trừ: Bênh nhân được chẩn đoán là UTĐM rốn gan nhưng không được chụp CHT hoặc không có kết quả giải phẫu bệnh, hoặc không đồng ý tham gia nghiên cứu, không có hồ sơ bệnh án đầy đủ

2.4 Phương pháp nghiên cứu: Tiến cứu, mô tả cắt ngang

2.5 Phương tiện và kỹ thuật chụp cộng hưởng từ: Bệnh nhân cần nhịn ăn trước khi chụp khoảng 4-6 giờ để giảm bớt hơi trong đường tiêu hóa và đề phòng trào ngược vào đường hô hấp trong trường hợp di ứng với thuốc đối quang từ, chống chỉ định CHT với bệnh nhân có dị vật và thiết bị kim loại đặt trong cơ thể.

Kỹ thuật: Thực hiện chụp trên máy CHT 1.5 Tesla. Các chuỗi xung sử dụng: T1W GRE: axial. T2W TSE: axial và coronal. Chuỗi xung đường mật MRCP lát cắt mỏng và dày, chuỗi xung khuếch tán (DWI). T1W 3Dfs, cắt lát mỏng $2 \mathrm{~mm}$ axial, trước và sau tiêm Gadolinium đường tĩnh mạch, liêu $0,2 \mathrm{ml} / \mathrm{kg}$, tốc độ tiêm $3 \mathrm{ml} / \mathrm{s}$, động học 3 thì động mạch giây thứ 30 sau khi bắt đầu tiêm, thì tĩnh mạch ở giây thứ 60 và thì muộn ở phút thứ 3 .

2.6. Quy trình và phương pháp thu thâp số liệu: Thu thập các thông tin về đặc điểm mẫu nghiên cứu như tuổi, giới, tiền sử các bệnh lý gan mật. Hình ảnh CHT được mô tả bởi bác sĩ chẩn đoán hình ảnh, đọc độc lập và không biết kết quả giải phẫu bệnh trước khi đối chiếu. Các đặc điểm $\mathrm{CHT}$ gồm: hình thái và kích thước $\mathrm{u}$, với thể thâm nhiễm, đo độ dày và chiều dài của đoạn đường mật hẹp. Đặc điểm tín hiệu $u$, đặc điểm hạn chế khuếch tán trên DWI/ADC. Đánh giá giai đoạn theo phân loại của Bismuth -
Corlette: loại I u dưới vị trí hợp lưu, loại II u tiếp giáp với hợp lưu, loại IIIA u phát triển vào ống gan phải, loại IIIB u phát triển vào ống gan trái, loại IV u phát triển vào cả hai ống gan phải và trái [4]. Kết quả đối chiếu với giải phâuu bệnh sau khi được sinh thiết hoặc phẫu thuật.

2.7. Xử lý và phân tích số liệu: nhập, phân tích bởi phần mềm SPSS 16.

2.8. Đạo đức nghiên cứu: Các số liệu, thông tin thu được từ bệnh nhân có sự đồng ý của Bệnh viện Hữu nghị Việt Đức.

\section{KẾT QUẢ NGHIÊN CỨU}

3.1. Đăc điểm hình ảnh của ung thư đường mật rốn gan trên cộng hưởng từ:

Trong thời gian từ 07/2019 đến 07/2021, chúng tôi tiến hành nghiên cứu trên 35 bệnh nhân với chẩn đoán lâm sàng UTĐM rốn gan, được chụp CHT tại Bệnh viện Hữu nghị Việt Đức. Trong đó, có 31 bệnh nhân được chẩn đoán xác định với kết quả giải phẫu bệnh UTĐM rốn gan, 04 bệnh nhân không phải UTĐM rốn gan. Đặc điểm hình ảnh $\mathrm{CHT}$ được phân tích trên 31 bệnh nhân UTĐM rốn gan.

3.1.1. Đặc điểm chung: Tuổi trung bình của các BN là $59,26 \pm 12,5$. Nam chiếm $71 \%$ và nữ chiếm 29\%. 22,6\% bênh nhân có tiền sử sỏi mật; $19,4 \%$ bệnh nhân có bệnh lý kết hợp khác ngoài sỏi mật.

3.1.2. Đặc điểm hình thái và kích thước u:

Trong 31 trường hợp UTĐM rốn gan, thể thâm nhiễm chiếm tỷ lệ cao nhất với 15 bệnh nhân (chiếm 48,4\%), thể khối gặp 13 bệnh nhân (chiếm 41,9\%), thể phát triển trong lòng đường mật có tỷ lệ thấp nhất với 3 bệnh nhân $(9,7 \%)$.

Với các u Klatskin thể khối và thể phát triển trong lòng đường mật, kích thước trung bình u là $3,86 \pm 1,77 \mathrm{~cm}$. $50 \%$ các $u$ có kích thước $<3 \mathrm{~cm}$.

Ở 15 trường hợp thể thâm nhiễm, độ dày thành đường mật là $6,53 \pm 4,04 \mathrm{~mm}$ (3,5$20,0 \mathrm{~mm}$ ). Chiều dài trung bình đoạn dày $25,47 \pm 6,87 \mathrm{~mm}(17-36 \mathrm{~mm})$.

3.1.3. Đăcc điểm tín hiệu u trên CHT: Trên CHT quy ước: Trên xung T1W, u giảm tín hiệu chiếm tỷ lệ cao nhất $(56,3 \%)$, đồng tín hiệu chiếm $37,5 \%$ và tăng tín hiệu chiếm tỳ lệ ít nhất (6,2\%). Trên xung T2W, ung thư đường mật rốn gan giảm tín hiệu trong 31,2\% trường hợp, đồng tín hiệu chiếm $12,5 \%$ và tăng tín hiệu chiếm tỷ lệ cao nhất 56,2\% trường hợp. Trên $\mathrm{CHT}$ khuếch tán: Trong 31 u Klatskin, có 30 trường hợp hạn chế khuếch tán (chiếm 96,8\%). Chỉ 1 trường hợp còn lại không hạn chế khuếch tán $(3,2 \%)$. 
3.2. Giá trị của cộng hưởng từ trong chẩn đoán xác định và đánh giá giai đoạn ung thư đường mật rốn gan:

3.2.1. Giá trị của CHT trong chẩn đoán xác định UTĐM rốn gan:

Bảng 1. Giá trị của CHT trong chẩn đoán xác định UTĐM rốn gan

\begin{tabular}{|c|c|c|c|}
\hline PHT/GPB & UTĐM rốn gan & $\begin{array}{c}\text { Không phải UTĐM } \\
\text { rốn gan }\end{array}$ & Tổng số \\
\hline UTĐM rốn gan & 31 & 3 & 34 \\
\hline Không phải UTĐM rốn gan & 0 & 1 & 1 \\
\hline Tống số & $\mathbf{3 1}$ & $\mathbf{4}$ & $\mathbf{3 5}$ \\
\hline
\end{tabular}

Từ bảng ta tính các giá trị: Độ nhạy $\mathrm{Se}=$ $31 / 31=100 \%$, độ đặc hiệu $\mathrm{Sp}=1 / 4=25 \%$, giá trị dự báo dương tính PPV $=31 / 34=91,2$ $\%$, giá trị dự báo âm tính NPV $=1 / 1=100 \%$, độ chính xác $=(31+1) / 35=91,4 \%$.

Nhận xét: Trong 35 đối tượng nghiên cứu, có 34 bệnh nhân được chẩn đoán UTĐM rốn gan trên CHT. Trong đó có 03 trường hợp dương tính giả. Hình ảnh cộng hưởng từ chẩn đoán là u Klatskin. Tuy nhiên, kết quả sau phẫu thuật và giải phẫu bệnh lần lượt là: ung thư túi mật xâm

lấn rốn gan; viêm liên quan đến đường mật xơ hóa liên quan đến IgG4 và viêm chít hẹp ngã ba đường mật. Ở bệnh nhân viêm đường mật xơ hóa liên quan đến IgG4, hình ảnh CHT gợi ý nguyên nhân ác tính: đường mật dày thành không đều 4,5mm trên đoạn dài $34 \mathrm{~mm}$, hạn chế khuếch tán trên Diffusion kèm ngấm thuốc mạnh sau tiêm. Tuy nhiên, kết quả giải phẫu bệnh trả lời viêm đường mật xơ hóa liên quan đến IgG4. Âm tính thật trong 1 trường hợp do viêm chít hẹp ngã ba đường mật.

3.2.2. Giá trị của CHT trong chẩn đoán giai đoạn UTĐM rốn gan theo phân loại của Bismuth - Corlette

Bảng 2. Giá trị của CHT trong chẩn đoán giai đoạn UTĐM rốn gan so sánh với phẫu thuật - giải phẫu bệnh

\begin{tabular}{|c|c|c|c|c|c|c|}
\hline CHT Phâu thuật & Loại I & Loại II & Loại IIIA & Loại IIIB & Loại IV & $\begin{array}{c}\text { Tống } \\
\text { số }\end{array}$ \\
\hline Loại I & 3 & 1 & 0 & 0 & 0 & 4 \\
\hline Loại II & 0 & 4 & 1 & 1 & 0 & 6 \\
\hline Loại IIIA & 0 & 0 & 5 & 0 & 1 & 6 \\
\hline Loại IIIB & 0 & 0 & 0 & 4 & 0 & 4 \\
\hline Loại IV & 0 & 0 & 0 & 1 & 10 & 11 \\
\hline Tống số & $\mathbf{3}$ & $\mathbf{5}$ & $\mathbf{6}$ & $\mathbf{6}$ & $\mathbf{1 1}$ & $\mathbf{3 1}$ \\
\hline
\end{tabular}

Nhận xét: Tỷ lệ chẩn đoán đúng loại I 100\%. Có 5 bệnh nhân loại II, trong đó 4 trường hợp chẩn đoán đúng trước mổ với tỷ lệ $80 \%, 1$ trường hợp chẩn đoán trước mổ giai đoạn I. Có 6 trường hợp loại IIIA, trong đó 5 trường hợp chẩn đoán đúng với tỷ lệ $83,3 \%, 1$ trường hợp chẩn đoán trước mổ giai đoạn II. Trong 6 trường hợp loại IIIB, có 4 trường hợp chẩn đoán đúng với tỷ lệ $66,7 \%, 1$ trường hợp chẩn đoán trước mổ giai đoạn II và 1 trường hợp giai đoạn IV. Trong 11 trường hợp loại IV, 10/11 trường hợp chẩn đoán đúng trước mổ chiếm tỷ lệ 90,9\%. 1 trường hợp chẩn đoán trước mổ ở giai đoạn IIIA. Như vậy trong tổng có 26/31 bệnh nhân được phân loại đúng giai đoạn trên MRI theo Bismuth Corlette, chiếm 83,9\%.

\section{BÀN LUÂN}

4.1. Đặc điểm hình ảnh cộng hưởng từ của ung thư đường mật rốn gan

Hình thái u: Trong nghiên cứu của chúng tôi, thể thâm nhiễm chiếm tỷ lệ cao nhất $48,4 \%$,

tiếp theo là thể khối chiếm 41,9\%, thể phát triển trong lòng đường mât có tỷ lệ thấp nhất $9,7 \%$. Theo các nghiên cứu trên thế giới, thể thâm nhiễm là thể hay gặp nhất, chiếm hơn $70 \%$ các trường hợp trong ung thư đường mật rốn gan, tiên lượng thường kém. Ngược lại, thể phát triển trong lòng đường mật ít gặp nhất nhưng lại là thể ít xâm lấn và có tiên lượng tốt nhất.

Kích thước u: Kích thước trung bình u Klatskin thể khối và thể phát triển trong lòng đường mật là $3,86 \pm 1,77 \mathrm{~cm}$. Với thể thâm nhiễm, độ dày thành đường mật trung bình là $6,53 \pm 4,04 \mathrm{~mm}$. Chiều dài trung bình đoạn dày là $25,47 \pm 6,87 \mathrm{~mm}$. Tác giả Yu nghiên cứu trên 28 BN UTĐM thể thâm nhiễm, độ dày trung bình là $4,4 \pm 1,2 \mathrm{~mm}$; chiều dài trung bình đoạn đường mật chít hẹp là $16,7 \pm 7,7 \mathrm{~mm}$ [5]. Trong khi đó ở $23 \mathrm{BN}$ dày thành đường mật lành tính, độ dày trung bình là $2,4 \pm 0,8 \mathrm{~mm}$ và chiều dài trung bình là $11,7 \pm 6,7 \mathrm{~mm}$. Nghiên cứu cũng chỉ ra đường mật dày $\geq 3,4 \mathrm{~mm}$ có độ nhạy và độ đặc hiệu $85,7 \%$ và $82,6 \%$ trong chẩn đoán dày đường 
mật ác tính [5].

Đặc điểm tín hiệu u trên CHT: $U$ giảm hoặc đồng tín hiệu trển chuối xung T1W chiếm $93,7 \%$, chỉ tỷ lệ nhỏ u tăng tín hiệu trên chuỗi xung T1W. Tín hiêu trên chuỗi xung T2W thay đổi nhưng tỷ lệ tăng tín hiệu vẫn là cao nhất $56,2 \%$. Theo Vũ Mạnh Hùng, 92,1\% UTĐM rốn gan giảm tín hiệu trên chuối xung T1W. Trên chuỗi xung $T 2 W$, các khối u đường mật thay đổi tín hiệu: tăng tín hiệu $48,6 \%$, đồng tín hiệu $42,8 \%$ và giảm tín hiệu $8,6 \%$ [6].Tín hiệu trển xung T2W của u đường mật thay đổi tùy thuộc mức độ xơ hóa, hoại tử và thành phần nhầy; u càng giàu $x \sigma$, ít thành phần nhây và hoại tử thì tín hiệu trên xung $T 2 W$ càng giảm [3].

Đắc điểm han chế khuếch tán: $96,8 \% \mathrm{u}$ Klastskin hạn chể khuếch tán (chiếm 96,8\%). Chỉ 3,2\% trường hợp còn lại không hạn chế khuếch tán. Theo Park và cộng sự, $100 \%$ trường hợp ung thư đường mật thể thâm nhiễm tăng tín hiệu trên $D W I$ với giá trị $B$ cao, kèm giảm tín hiệu trền $A D C$ map chiếm $92,9 \%$ và đồng tín hiệu $7,1 \%$. Kết hợp DWI/ADC với các chuỗi xung CHT thường quy giúp tăng giá trị chẩn đoán chính xác ung thư đường mật từ 78-81\% lên 91-94\%[7].

4.2. Giá trị của CHT trong chẩn đoán và phân chia giai đoạn UTĐM rốn gan:

4.2.1. Giá trị của CHT trong chẩn đoán xác định UTĐM rốn gan: Trong nghiên cứu của chúng tôi, cộng hưởng từ có độ nhạy = $31 / 31(100 \%)$, độ đặc hiệu $=1 / 4(25 \%)$, giá trị dự báo dương tính $91,2 \%$, giá tri dự báo âm tính $=100 \%$, độ chính xác 91,4\%. Theo Vanderveen và cộng sự, độ nhạy và độ đặc hiệu của MRCP trong chẩn đoán ung thư đường mật là $81 \%$ và $100 \%$ [3].Theo Park và cộng sự, độ chính xác của cộng hưởng từ trong chẩn đoán phân biệt tắc mật ác tính và lành tính là 91,3\% đến 94,2\% [7]. Theo Yu và cộng sự, cộng hưởng từ chẩn đoán đúng 92,9\% ung thư đường mật, 91,3\% hẹp đường mật lành tính, độ chính xác $92,2 \%$ [5]. Theo Vũ Mạnh Hùng, $\mathrm{CHT}$ có độ nhạy $100 \%$, độ đặc hiệu $33,3 \%$, độ chính xác 96,1\% trong chẩn đoán ung thư đường mật rốn gan [6]So sánh với các tác giả khác, độ nhạy, giá trị dự báo dương tính và giá trị dự báo âm tính trong nghiên cứu của chúng tôi nhìn chung tương đương hoặc cao hơn; trong khi đó độ đặc hiệu thấp hơn. Vì là bệnh viện tuyến cuối, các bệnh nhân được chụp cộng hưởng từ khi đến với chúng tôi thường đã có kết quả xét nghiệm, siêu âm hoặc chụp CLVT/CHT ở tuyến trước, vì vậy độ nhạy trong chẩn đoán rất cao. Hầu hết bệnh nhân ung thư đường mật không bị bỏ sót trên cộng hưởng từ (độ nhay 100\%). Tuy nhiên độ đặc hiệu thấp. Chúng tổi có 03 trường hợp chẩn đoán nhầm (dương tính giả). Trường hợp dương tính giả, hình ảnh CHT gợi ý nguyên nhân ác tính, tuy nhiên kết quả giải phẫu bệnh là viêm đường mật xơ hóa liên quan đến IgG4. Dày thành, ngấm thuốc mạnh cũng như hạn chế khuếch tán của đường mật ở đây được giải thích bởi sự xâm nhập lan tỏa của lympho tương bào từ lớp niêm mạc ra lớp thanh mạc, quá trình viêm mạn tính và xơ hóa. Viêm đường mật xơ hóa liên quan đến IgG4 thể đơn độc không kèm theo tổn thương cơ quan khác có các đặc điểm rất giống và khó phân biệt trên cộng hưởng từ với ung thư đường mật thể thâm nhiễm [7]. Chẩn đoán dựa trên chẩn đoán hình ảnh, giải phẫu bệnh, tăng nồng độ IgG4 trong huyết thanh và đáp ứng điều trị với corticoid.

4.2.1. Giá trị của CHT trong đánh giá giai đoạn UTEM rốn gan: Trong tổng số 31 bệnh nhẩn, 83,9\% được chẩn đoán đúng giai đoạn trên MRI theo phân loại của tác giả Bismuth Corlette, 5 bệnh nhân chẩn đoán chưa đúng giai đoạn, chiếm 16,1\%. Giai đoạn Bismuth Corlette có ý nghĩa đánh giá mức lan rộng của ung thư đường mật rốn gan lên ống gan hai bên. Theo nghiên cứu tổng hợp của tác giả Ruys và cộng sự, độ chính xác của cộng hưởng từ trong chẩn đoán giai đoạn ung thư đường mật rốn gan từ $71 \%$ đến $80 \%$. Trong khi đó, độ chính xác trung bình của CT cao hơn $86 \%(77-92 \%)$, của siêu âm là $59 \%$ - 82\% [8]. Tỷ lệ chẩn đoán đúng giai đoạn của u Klatskin trong nghiên cứu của chúng tôi là cao hơn các nghiên cứu trước đó. Sứ kết hợp của nhiều chuỗi xung đặc biệt là chuối xung khuếch tán và kết hợp tiêm thuốc đối quang từ giúp chẩn đoán tương đối chính xác mức độ lan rộng của u. Ở các trường hợp chẩn đoán sai, giai đoạn được chẩn đoán thường thấp hơn so với giai đoạn trong phẫu thuật và giải phẫu bệnh do chưa đánh giá hết sự lan rộng của u, nhất là khi u mới lan vào đầu ngã ba hợp lưu hoặc đầu ống gan hai bên.

\section{KẾT LUÂNN}

Qua nghiên cứu chúng tôi thấy cộng hưởng từ có độ nhạy, giá trị dự báo dương tính, giá trị dự báo âm tính, độ chính xác cao trong chẩn đoán xác định ung thư đường mật rốn gan. Cộng hưởng từ cũng giúp đánh giá chính xác giai đoạn u theo phân loại Bismuth - Corlette, đưa ra thông tin quan trọng cho lâm sàng để có kế hoạch điêu trị thích hợp. Cộng hưởng từ là phương pháp rất có giá trị trong chẩn đoán và 
đánh giá giai đoạn ở bệnh nhân ung thư đường mật rốn gan.

\section{TÀI LIÊU THAM KHẢO}

1. Klatskin G. (1965). Adenocarcinoma of the hepatic duct at its bifurcation within the porta hepatis. The American Journal of Medicine, 38(2), 241-256.

2. Lim J.H. (2012). Cholangiocarcinoma: Morphologic Classification According to Growth Pattern and Imaging Findings. American Journal of Roentgenology.

3. Vanderveen K.A. and Hussain H.K. (2004). Magnetic resonance imaging of cholangiocarcinoma. Cancer Imaging, 4(2), 104-115.

4. Bismuth H. and Corlette M.B. (1975). Intrahepatic cholangioenteric anastomosis in carcinoma of the hilus of the liver. Surg Gynecol Obstet, 140(2), 170-178.
5. Yu X.-R., Huang W.-Y., Zhang B.-Y., et al. (2014). Differentiation of infiltrative cholangiocarcinoma from benign common bile duct stricture using three-dimensional dynamic contrastenhanced MRI with MRCP. Clin Radiol, 69(6), 567-573.

6. Vũ Manh Hùng (2007), Đặc điểm hình ảnh và giá trị của cộng hưởng từ trong chẩn đoán ung thư đường mật rốn gan, Luận văn tốt nghiệp bác sĩ nôii trú bênh viên, Đai họ Y Hà Nối.

7. Park M.j., Kim Y.K., Lim S., et al. (2014). Hilar cholangiocarcinoma: value of adding DW imaging to gadoxetic acid-enhanced MR imaging with MR cholangiopancreatography for preoperative evaluation. Radiology, 270(3), 768-776.

8. Ruys A.T., Van Beem B.E., Engelbrecht M.R.W., et al. (2012). Radiological staging in patients with hilar cholangiocarcinoma: a systematic review and meta-analysis. $\mathrm{Br}]$ Radiol, 85(1017), 1255-1262.

\section{ĐĂC ĐIỂM MÔ CỨNG TRÊN PHIM SỌ NGHIÊNG TỪ XA TRƯỚC ĐIỀU TRI CỦA BÊNH NHÂN SAI KHỚP CẮN LOẠI II TIỂU LOẠI 1 CÓ NHỔ BỐN RĂNG HÀM NHỎ}

\section{TÓM TẮT}

Mục tiêu: Nhận xét đặc điểm mô cứng trên phim so nghiêng từ xa trước điêù trị của bệnh nhân sai khớp cẳn loại II tiểu loại 1 có nhổ bốn răng hàm nhỏ. Đối tượng và phương pháp nghiên cứu: Nghiên cứu mồ tá dựa trên đo đạc phim sọ nghiêng từ xa trước điều trị của 31 bệnh nhân (21 nữ, 10 nam) sai khớp cắn loại II tiểu loại 1 có nhổ bốn răng hàm nhỏ tại Viên Đào tao Răng Hàm Măt và Bênh viên Răng Hàm Mặt Trung Ương Hà Nội đển tháng 6/2021. Kết quả nghiên cứu: Tuổi trung bình 18,65 (11- 34). Tương quan xương hàm trên với nền sọ bình thường: góc SNA $83,74 \pm 3,40^{\circ}$. Xương hàm dưới lùi: góc SNB

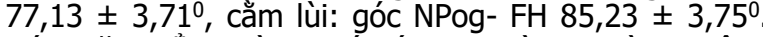
Góc mặt phằng hàm dưới lớn hơn bình thường, bệnh nhân có hướng phát triển theo chiêu dọc. Góc ANB $6,58^{\circ}$, chỉ số Wits $2,73 \mathrm{~mm}$ lớn hơn bình thường chứng tó có sự bất cân xứng hai xương hàm theo chiều trước sau. Rắng cửa trên và dưới ngả ra trước rất nhiều so với nền sọ, mặt phẳng hàm trên và hàm dưới. Góc liên trục răng cửa 109,79 $\pm 8,08^{\circ}$ nhỏ hơn bình thường cho cho thấy vẩu răng cửa hai hàm. Độ cắn chìa lớn $5,75 \pm 3,08 \mathrm{~mm}$. Kết luận: Bệnh nhân sai khớp cắn loại II tiểu loại 1 có nhổ bốn răng hàm nhỏ có góc SNA

1 Viện Đào Tạo Răng Hàm Mặt, Đại học Y Hà Nội ²Bểnh viên Răng Hàm Mặt Trung Ương Hà Nội Chịu trách nhiệm chính: Đố Lê Phương Thảo Email: Dolephuongthaorhm@gmail.com Ngày nhận bài: 24.6.2021

Ngày phản biên khoa hoc: 24.8.2021

Ngày duyệt bài: 30.8.2021

\section{Đỗ Lê Phương Thảo1, Võ Thị Thúy Hồng², Nguyễn Thị Thu Phương ${ }^{1}$}

bình thường, góc SNB nhỏ hơn bình thường, cằm lùi, góc $A N B$ và chỉ số Wits tăng. Xu hướng phát triển theo hướng mở. Răng cửa hai hàm ngả trước và nằm ở vị trí ra trước, vẩu răng cửa hai hàm. Đô cắn chìa lớn.

Từ khóa: mô cứng, khớp cắn loại II tiểu loại 1 , phim sọ nghiêng, răng hàm nhỏ, nhổ rằng

\section{SUMMARY \\ HARD TISSUE CHARACTERISTICS OF CLASS II DIVISION 1 MALOCCLUSIONS WITH FOUR PREMOLARS EXTRACTION BY EVALUATE PRE-TREATMENT LATERAL CEPHALOMETRIC RADIOGRAPHY}

Objectives: To evaluate the pre- treatment cephalometric characteristics of hard tissue of class II division 1 malocclusions with four premolars extraction. Materials and method: Descriptive study of 31 patients (21 females, 10 males) diagnosed with class II division 1 malocclusion with four premolars extraction in School of Odonto- Stomatology and National Hospital Of Odonto- Stomatology to June 2021 were recruited. Results: The average of age was 18,65 (range in 11 to 34 ). Normal SNA angle $83,74 \pm 3,40^{\circ}$. Retruded mandibular and Pogonion point with SNB angle $77,13 \pm 3,71^{\circ}$ and NPog- $\mathrm{FH}$ angle $85,23 \pm 3,75^{\circ}$ were less than normal range. Mandible angle was greater showed a generalized tendency towards a more vertical skeletal growth pattern. The greater ANB angle $6,58^{\circ}$ and Wits appraisal $2,73 \mathrm{~mm}$. Severe bimaxillary proclination in relation to anterior cranial base, palatal plane and mandible plane. Interincisal angle $109,79 \pm 8,08^{\circ}$ was less than normal. Large overjet was 5,75 $\pm 3,08 \mathrm{~mm}$. 